JURNAL SEHAT MASADA VOLUME $\quad$ XVI NOMOR $1 \quad$ Januari $2022 \quad$ ISSN : 1979-2344

\title{
PENGARUH PENDIDIKAN KESEHATAN TENTANG BANTUAN HIDUP DASAR (BHD) TERHADAP PENGETAHUAN BANTUAN HIDUP DASAR PETUGAS KEBERSIHAN DI STIKES DHARMA HUSADA BANDUNG
}

\author{
Sanita Fitri $\mathrm{S}^{1}$, Hery Prayitno ${ }^{2}$, Hilman Firmansyah ${ }^{3}$ \\ ${ }^{1}$ Mahasaiwa Program Studi Diploma Tiga Keperawatan STIKes Dharma Husada Bandung \\ ${ }^{2}$ Dosen Program Studi Diploma Tiga Keperawatan STIKes Dharma Husada Bandung \\ ${ }^{3}$ Dosen Program Studi Sarjana Keperawatan STIKes Dharma Husada Bandung \\ heryprayitno007@gmail.com
}

\begin{abstract}
Abstrak
Kejadian korban mengancam nyawa yang terjadi diluar rumah sakit yang mendasari pentingnya memahami bantuan hidup dasar, tidak hanya oleh tenaga medis dan perawat tetapi juga penolong awam secara luas. Petugas kebersihan merupakan salah satu dari golongan orang awam yang sangat berpotensi menemukan korban gawat darurat dilingkungan kampus dan sekitarnya. Dengan pengetahuan yang dimiliki akan meningkatkan angka keberhasilan dan survival rate pada pasien henti jantung. Tujuan : Penelitian ini bertujuan untuk mengetahui Pengeruh Pendidikan Kesehatan tentang Bantuan Hidup Dasar terhadap pengetahuan Petugas Kebersihan di STIKes Dharma Husada Bandung. Jenis penelitian yang digunakan ialah Pre-Eksperimen dengan menggunakan one grup pretest-posttest design. Sampel sebanyak 14 responden dengan menggunakan sampel jenuh.Menggunakan uji statistik $\mathrm{t}$ berpasangan didapat nilai $\mathrm{p}$ value $=0.000<0.05$. Menunjukan adanya pengaruh antara pengetahuan sebelum dan sesudah diberikan pendidikan kesehatan. Perlunya pendidikan kesehatan tentang bantuan hidup dasar pada masyarakat awam agar dapat diterapkan di lingkungan masyarakat.
\end{abstract}

Kata kunci : Bantuan Hidup Dasar, Pendidikan Kesehatan, Pengetahuan Petugas Kebersihan.

\section{PENDAHULUAN}

Kegawatdaruratan merupakan suatu kejadian yang terjadi secara tiba-tiba yang dapat disebab oleh kejadian alam, bencana teknologi, perselisihan atau kejadian yang disebabkan oleh manusia, dan menuntut suatu penanganan secara cepat. Kejadian gawat darurat dapat menimpa siapa saja dan terjadi dimana dan kapan saja (Muthmainnah, 2019).

Kejadian henti jantung merupakan salah satu kondisi kegawatdaruratan yang banyak terjadi di luar rumah sakit. Sekitar 350.000 individu dewasa di Amerika Serikat mengalami henti jantung di luar rumah sakit (OHCA) nontraumatik dan ditangani oleh personel layanan medis darurat (EMS). Kurang dari $40 \%$ individu dewasa menerima CPR yang dimulai oleh individu awam, dan kurang dari $12 \%$ yang menerapkan defibrilator eksternal otomatis (automated external defibrilator/AED) sebelum kedatangan EMS (AHA, 2020). Di indonesia, data prevalensi yanng didapatkan untuk cardiac arrest tiap tahunya belum jelas, tetapi diperkirakan terdapat sekitar 10.000 warga indonesia yang mengalami cardiac arrest, dari data PERKI 
pada tahun 2016 menemukan bahwa angka kejadian henti jantung mendadak berkisar antara 300.000-350.000 insiden setiap tahunnya (Muthmainnah, 2019).

Kejadian korban mengancam nyawa yang terjadi diluar rumah sakit inilah yang mendasari pentingnya memahami bantuan hidup dasar, tidak hanya oleh tenaga medis dan perawat tetapi juga penolong awam secara luas. Pendidikan kesehatan tentang bantuan hidup dasar (basic cardiac life support) yang terdiri dari tindakan resusitasi jantung paru pada penolong awam menjadi hal utama untuk meningkatkan kemampuan menolong korban mengancam nyawa dan mengetahui penatalaksana korban tidak sadarkan diri diluar rumah sakit yang bisa menyebabkan henti jantung (Suharsono \& Ningsih, 2014). Dan pentingnnya CPR dini yang dilakukan oleh penyelamat awam telah ditekankan kembali.

Berdasarkan hasil literatur effect of life support training on knowledge and preparatory school teachers in Sheben Elkom City, Menoufia Gevonernorate, Egypt. Sampel sebanyak 300 guru yang berpartisipasi dalam penelitian, menggunakan teknik random sampling, dengan jenis kelamin dominan lakilaki $(79,7 \%)$ dan status sosial menengah $(84,3 \%)$. Nilai rata-rata pengetahuan dan praktik pretest $(2,04 \pm 2,4) \&(3,44 \pm 0,85)$. Nilai pengetahuan dan parktik post-test $(10,1 \pm$ $1,8) \&(7,46 \pm 1,4)$ dengan demikian dengan program bantuan hidup dasar saat ini berhasil meningkatkan pengetahuan dan pratik guru sekolah (Safa, 2019).
Berdasarkan hasil penelitian pengaruh pendidikan bantuan hidup dasar terhadap pengetahuan anggota unit kegiatan mahasiswa tim kesehatan sarjana keperawatan STIKes Dharma Husada Bandung. Dengan hasil pengetahuan sebelum dilakukan pendidikan kesehatan nilai rata-rata sebesar 47,20 dengan kategori kurang (64\%), dan setelah diberikan pendidikan kesehatan terjadi peningkatan pengetahuan dengan nilai rata-rata 66,53 dengan kategori baik (44\%) (Deris, 2020). Selain itu menurut literatur Pengaruh penyuluhan terhadap pengetahuan mengenai bantuan hidup dasar pada anggota SAT lantas SABHARA (Patroli Quick Respon) diperoleh hasil penelitian sebelum diberikan penyuluhan BHD nilai rata-rata adalah 44,05 dan setelah diberikan penyuluhan BHD dengan nilai ratarata 79,92. Hal ini mengindikasikan bahwa tingkat pengetahuan anggota sat sabhara diberi penyuluhan BHD lebih baik baik dibandingkan sebelum penyuluhan (Putri, 2019).

Bantuan hidup dasar adalah usaha yang dilakukan untuk menjaga jalan napas (airway) tetap terbuka, menunjang pernapasan (breathing) dan sirkulasi (circulation) tanpa menggunakan alat bantu berdasarkan survai primer yang dilakukan. Usaha BHD bertujuan secara cepat mempertahankan pasok oksigen ke otak, jantung dan organ vital lainnya sampai menunggu pengobatan lanjutan/ bantuan hidup jantung. Pengalamann menunjukkan bahwa resusitasi jantung paru akan berhasil terutama pada henti jantung paru akan berhasil terutama pada henti jantung yang disaksikan (witnessed) 
JURNAL SEHAT MASADA VOLUME XVI

sehingga setiap orang sebaiknya dapat melakukan (Adrianto, 2019).

STIKes Dharma Husada Bandung merupakan kampus yang berdiri dibidang kesehatan yang mana harus memiliki dampak besar terhadap lingkungan sekitar, kejadian korban tidak sadarkan diri atau mengancam nyawa yang menemukan korban ditempat diantaranya mahasiswa, staf keamanan dan petugas kebersihan. Ketika petugas kebersihan menemukan korban langsung segera dibawa ke klinik kampus untuk mendapatkan tindakan lebih lanjut tanpa dilakukan penilaian status kesadaran, pernapasan, denyut nadi dan tingkat cedera korban. Petugas kebersihan orang yang pertama datang dan paling akhir ketika pulang yang berpotensi menemukan korban tidak sadarkan diri. Dan petugas kebersihan juga tidak dibekali pengetahuan mengenai bantua hidup dasar. Hasil studi pendahuluan melalui wawancara yang dilakukan oleh peneliti pada 5 orang petugas kebersihan di kampus STIKes Dharma Husada Bandung. Didapatkan informasi bahwa 4 orang petugas kebersihan belum pernah mengikuti pelatihan atau pendidikan kesehatan mengenai BHD dengan alasan petugas kebersihan adalah karyawan baru, dan 1 orang mengetakan sudah pernah mengikuti pelatihan sekitar 3 tahun yang lalu namun sudah lupa dengan langkah-langkah melakukan BHD. Dan sementara itu menurut American Heart Association (2015) Basic Life Support atau Bantuan Hidup Dasar dapat dilakukan oleh siapapun tidak harus dari tenaga kesehatan.

Jurnal Penelitian Kesehatan STIKes Dharma Husada Bandung 
JURNAL SEHAT MASADA VOLUME XVI

kategori kurang sebanyak 10 atau $71.4 \%$ dan kategori baik sebanyak 0. Dengan demikian kategori terbanyak yaitu berkategori kurang sebesar $71.4 \%$.

Pengetahuan Petugas Kebersihan di STIKes Dharma Husada Bandung Sesudah Diberikan Pendidikan Kesehatan.

Tabel 2

Pengetahuan Setelah Pendidikan Kesehatan

\begin{tabular}{lcc}
\hline \multicolumn{1}{c}{ Kategori } & N & \% \\
\hline Baik & 8 & 57.1 \\
\hline Cukup & 6 & 42.9 \\
\hline Kurang & 0 & 100 \\
\hline
\end{tabular}

Pada Tabel 2 diketahui mengenai pengetahuan

Petugas Kebersihan di STIKes Dharma Husada

Bandung, dengan jumlah reponden 14, nilai terendah 65 dan nilai tertinggi 100. Jumlah kategori Baik sebanyak 8 atau 57.1\%, kategori cukup sebanyak 6 atau $42.9 \%$ dan kategori kurang sebanyak 0 . Kategori terbanyak yaitu berkategori baik sebesar $57.1 \%$.

Pengaruh Pendidikan Kesehatan tentang Bantuan Hidup Dasar Terhadap Pengetahuan Petugas Kebersihan di STIKes Dharma Husada Bandung.

Tabel 3

Pengaruh Pendidikan Kesehatan

\begin{tabular}{lcccc}
\hline & N & Min/Max & Mean & $\begin{array}{c}P \\
\text { value }\end{array}$ \\
\hline Pretest & 14 & $37.5 / 56.0$ & 46.8 & \multirow{2}{*}{0.000} \\
\hline Posttest & 14 & $74.3 / 85.6$ & 80.0 & \\
\hline
\end{tabular}

Tebel 3 menunjukan bahwa skor pengetahuan reponden sebelum diberikan pendidikan kesehatan rata-rata sebesar 46,8\% kemudian setelah diberikan pendidikan kesehatan skor rata-rata pengetahuan responden sebesar $80 \%$. Dengan demikian pengetahuan responden mengalami peningkatan sebanyak $33.2 \%$.

Berdasarkan hasil output statistis Paired Sample T-Test Berpasangan antaran hasil pretest dan posttest adalah, hal tersebut menunjukan bahwa ada peningkatan pengetahuan Petugas Kebersihan di STIKes Dharma Husada Bandung. Hasil Uji T test bernilai $p=.000(<.0,5)$ maka hasil hasil uji Paired Sample T-test Berpasangan yaitu Ha diterima dan Ho ditolak, sehingga dapat disimpulkan pula bahwa ada pengaruh pendidikan kesehatan tentang bantuan hidup dasar terhadap pengetahuan.

\section{B. PEMBAHASAN}

\section{Pengetahuan Petugas Kebersihan di STIKes Dharma Husada Bandung Sebelum Diberikan Penyuluhan.}

Hasil penelitian pengetahuan Petugas Kebersihan di STIKes Dharma Husada Bandung sebelum diberikan pendidikan kesehatan tentang bantuan hidup dasar dengan jumlah 14 orang, jumlah kategori cukup sebanyak 4 atau $28.6 \%$, kategori kurang sebanyak 10 atau $71.4 \%$ dan baik sebanyak 0 . Sebelum diberikan pendidikan kesehatan 12 responden mengatakan belum pernah diberikan materi tentang bantuan hidup dasar sehingga responden kurang mengetahui mengenai bantuan hidup dasar hanya pernah melihat atau mengetahui melalui internet atau berita 
JURNAL SEHAT MASADA VOLUME XVI

sehingga kurang dapat mahami dan dipraktekkan, dan dua orang responden mengatakan sudah pernah mendapatkan pelatihan terkait bantuan hidup dasar namun responden sudah lupa dikarenakan pelatihan yang pernah diikuti sudah sekitar 3 tahun yang lalu. Pengetahuan seseorang dapat dipengaruhi oleh beberapa faktor diantaranya usia, informasi, pekerjaan, pendidikan, pengalaman, dan social budaya (Noatoatmodjo, 2014).

Menurut penelitian Swansanti \& Putra (2014) penolong awam merupakan jenis penolong pertama dan tidak terlatih. Dia hanya mempraktikkan apa yang dia pernah lihat.Pengetahuan kurang pada penelitian ini disebabkan hampir semua reponden salah menjawab pada pengertian, tujuan, alogaritma dan langkah-langkah BHD. Menurut AHA (2015) Basic Life Support atau Bantuan Hidup Dasar dapat dilakukan oleh siapapun tidak harus dari tenaga kesehatan. Berkaitan dengan bantuan hidup dasar pengetahuan penolong awam biasa maupun awam khusus sama-sama memagang peranan dalam pemberian bantuan hidup dasar pada kasus henti jantung dan napas, yang akan meningkatkan angka keberhasilan dan survival rate pada pasien henti jantung.

\section{Pengetahuan Petugas Kebersihan di STIKes Dharma Husada Bandung Sesudah Diberikan Penyuluhan.}

Hasil penelitian menujukan bahwa jumlah kategori baik sebanyak 8 atau $57.1 \%$, kategori cukup sebanyak 6 atau $42.9 \%$ dan kurang sebanyak 0. Dengan demikian data tersebut menunjukkan bahwa terdapat peningkatan pengetahuan yang signifikan antara sebelum dan sesudah intervensi. Pada penelitian ini terdapat 6 responden dengan nilai cukup atau $42.9 \%$, dengan jumlah pertanyaan yang salah terbanyak yaitu mengenai pengertian bantuan hidup dasar, resusitasi jantung paru dan tujuan dari BHD. Menurut Notoatmojo (2010), perubahan tingkat pengetahuan dan keterampilan disebabkan karena pada pelatihan bantuan hidup dasar terdapat pemberian informasi, dimana didalamnya terdapat proses belajar.

Hasil penelitian ini sejalan dengan penelitian yang dilakukan oleh Herry, Putri dan Deris (2020) tentang Pengaruh Pendidikan Kesehatan Bantuan Hidup Dasar Terhadap Pengetahuan Anggota Unit Kegiatan Mahasiswa Tim Kesehatan Sarjana Keperawatan STIKes Dharma Husada Bandung, bahwa terdapat nilai signifikan antara sebelum dilakukan intervensi pendidikan kesehatan sebesar $64 \%$ berkategori kurang dan setelah dilakukan intervensi yaitu sebesar $44 \%$ berkategori baik. Faktor yang berpengaruh terhadap baikknya pengetahuan yaitu sumber informasi.

\section{Pengaruh Pendidikan Kesehatan Tentang Bantuan Hidup Dasar Terhadap Petugas Kebersihan di STIKes Dharma Husada Bandung.}

Setelah dilakukan uji normalitas didapat nilai signifikan Pretest $\mathrm{p}=0,121$, Posttest $\mathrm{p}=0,491$ dapat diketahui hasil normalitas 
JURNAL SEHAT MASADA VOLUME XVI

berdistribusi normal. Penelitian ini menggunakan uji analisis $\mathrm{t}$ berpasangan. Setelah di uji $\mathrm{t}$ didapatkan hasil $\mathrm{p}$ value $=$ 0.000 sehingga dapat diketahui pendidikan kesehatan memiliki pengaruh terhadap tingkat pengetahuan Petugas Kebersihan mengenai bantuan hidup dasar. Pendidikan kesehatan sebelum kategori terbanyak yaitu kurang sebanyak $71,4 \%$, kemudian sesudah diberikan pendidikan kesehatan dengan kategori baik $57,1 \%$.

Penelitian Resmi, Mindo \& Asima (2017) dengan hasil terdapat pengaruh yang signifikan dimana diperoleh hasil $\mathrm{p}$ value $0,000<0,05$, jumlah peserta 30 orang dengan nilai rata-rata sebelum diberikan pendidikan kesehatan sebanyak 19,0\% dan sesudah diberikan Pendidikan kesehatan sebanyak 75,2\%. Hal ini sejalan dengan peelitian Pengaruh penyuluhan terhadap pengetahuan mengenai bantuan hidup dasar pada anggota SAT lantas SABHARA (Patroli Quick Respon) diperoleh hasil penelitian sebelum diberikan penyuluhan BHD nilai rata-rata adalah 44,05 dan setelah diberikan penyuluhan BHD dengan nilai rata-rata 79,92. Hal ini mengindikasikan bahwa tingkat pengetahuan anggota sat sabhara diberi penyuluhan BHD lebih baik baik dibandingkan sebelum penyuluhan (Putri, 2019).

Pengetahuan tentang Bantuan Hidup Dasar (BHD) sangat diperlukan oleh seluruh kalangan masyarakat. Hal ini sejalan dengan penelitian Meissner (2012) anak umur $13-14$ telah dapat melakukan resusitasi jantung paru
NOMOR 1 Januari 2022

ISSN : 1979-2344

sama baiknya dengan orang dewasa. Peranan orang awam dalam hal ini menjadi sangat penting, untuk peningkatan harapan hidup sesorang melalui pengetahuan dan kemampuan melakukan Bnatuan Hidup Dasar (BHD), oleh karena itu pemberian informasi baik berupa pendidikan kesehatan, simulasi BHD perlu dilakukan kontinu.

Bantuan hidup dasar merupakan salah satu rangkaian dari rangkaian pertolongan henti jantung dan henti napas yang terdiri dari IHCA (In Hospital Cardiac Arrest) dan OCHA ( Out Of Hospital Cardiac Arrest). Penelitian ini berfokus pada OCHA dengan alogaritma : Aktivasi respond darurat, CPR kualitas tinggi, defibrilasi, resusitasi lanjutan, perawatan pasca-henti jantung, dan pemulihan. BHD meupakan rangkaian penting dan tidak dapat dipisahkan.

\section{KESIMPULAN}

Berdasarkan hasil penelitian terhadap 14 responden yang telah dilakukan kepada Petugas Kebersihan di STIKes Dharma Husada Bandung dapat disimpulkan bahwa :

1. Petugas Kebersihan sebelum diberikan pendidikan kesehatan terdapat kategori cukup sebanyak 4 orang atau $28.6 \%$, kategori kurang sebanyak 10 orang atau $71.4 \%$ dan baik sebanyak 0 .

2. Petugas Kebersihan setelah diberikan pendidikan kesehatan kategori baik sebanyak 8 orang atau $57.1 \%$, kategori cukup sebanyak 6 orang atau $42.9 \%$ dan kategori kurang sebanyak 0 . 
3. Setelah dilakukan Uji T-test berpasangan dengan hasil $0.00<0,05$ maka adanya pengaruh pendidikan kesehatan tentang bantuan hidup dasar terhadap pengetahuan Petugas Kebersihan di STIKes Dharma Husada Bandung. Dengan demikian pendidikan kesehatan dapat meningkatkan pengetahuan Petugas Kebersihan di STIKes Dharma Husada Bandung.

\section{DAFTAR PUSTAKA}

Hermayudi. Ayu. 2017. Keperawatan Medik. Yogyakarta : Muha Medika.

Ika. Tony. Ikhdal dkk. 2019. Pertolongan Pertama Gawat Darurat (PPGD). Malang : UB Press.

Andrianto. 2019. Buku Ajar Kegawatdaruratan kardiovaskular. Surabaya : Airlangga University Press.

Maisarah. Dewi. 2020. Pertolongan Pertama Reaksi Sigap Menyelamatkan Nyawa. Sidoarjo : Zifatama Jawara.

Safa. 2019. Effect of Basic Life Support Training on Knowledge and Preparatory School Teachers in Sheben Elkom City, Menoufia Governorate, Egypt. Vol 3. Issue 2. DOI : 10.21608/EFMJ.2019.70438.

Deris. Herry. Putri. 2020. Penggaruh Pendidikan Kesehatan Tentang Bantuan Hidup Dasar Terhadap Pengetahuan Anggota Unit Kegiatan Mahasiswa Tim Kesehatan Sarjana Keperawatan Tingkat 1 STIKes Dharma Husada Bandung. Vol 4. No 2. P-ISSN : 2715-8748
American Heart Association. (2020).Highlights of 2020 American Heart Association Guidelines Update for CPR dan ECC.USA : American Heart Association

Latifah, Putri. 2019. Pengaruh Penyuluhan Terhadap Pengetahuan Mengenai Bantuan Hidup Dasar (BHD) pada Anggota SAT Sabhara ( Patroli Quick Respon) di Polrestabes Bandung. Bandung : STIKes Dharma Husada Bandung.

Riskesdas. 2018. Hasil Utama Riskesdas. Jakarta : Badan Penelitian dan Pengembangan Kesehatan, Kementrian Kesehatan RI.

Muthamainnah. 2019. Hubungan Tingkat Pengetahuan Awam Khusus Tentang Bantuan Hidup Dasar Berdasarkan Karakteristik Usia Di RSUD X Hulu Sunggai Selatan. Vol 2. No 2. ISSN : 29973841

Sudarman. Akbar. Irmiatinarahma. 2019. Pengaruh Pelatihan Hidup Dasar Terhadap Pengetahuan Sisiwa Kelas XII di SMK Baznas Sulsel. Vol 1. p-ISSN: 2657-2281

Safia. Lucky. Reginus. 2017. Pengaruh Pendidikan Kesehatan Terhadap Tingkat Pengetahuan Bantuan Hidup Dasar (BHD) Pada Kecelakaan Lalu Lintas Pada Siswa SMA Negeri 1 Sanana Kabupaten Kepulauan Sula Maluku Utara. Vol 5 No 1.

Resmi. Mindo. Asima. 2017. Pengaruh Media Pendidikan Kesehatan Terhadap Pengetahuan Bantuan Hidup Dasar (BHD) (Studi Ekperimen Pada Perawat Pelaksana di Rumah Sakit TK. II Putri Hijau Medan Tahun 2017). Vol 3 No 1. 